\title{
Contribuições Parafiscais: Natureza, Classificação e Distinção
}

\section{Chagas Melo}

Embora não se tenha ainda definido rigorosamente o conceito de contribuições parafiscais, o Autor, estribado em valiosas opiniōes de renomados técnicos e professôres de finanças, procura definir, classificar e distinguir a espécie, terminando por aconselhar o seu enquadramento no orçamento da União, mediante dispositivo legal, a fim de que tais contribuiçôes se revistam cla qualidade de verdadeiro tributo.

A tese vem ao encoritro da opinião de iltustre Ministro do Tribunal de Contas, iá publicada na R.S.V. de outubro de 1958; "são incontáveis os maleficios da ruptura causada pela parafiscalidade à unidade e à universalidade do orçamento, bem como ao contrôle dos dinheiros públicos...".

A "parafiscalidade" contém algo nôvo e inconfundivel como instituto fiscal no sistema tributário brasileiro. E' uma espécie, como o impôsto, a taxa e a contribuição de melhoria, do gênero tributo, porém com características especiais.

Recentemente, diz o Professor Aliomar Baleeiro "popularizou-se a denominação de contribuiçốes parafiscais dada às receitas dos institutos de previdência e organismos profissionais autônomos e investidos de delegação do poder fiscal, para aplicação de tais arrecadações aos fins que as justificam. Rigorosamente, essas contribuições parafiscais são ora taxas, ora impostos, uu consociaçốes dêstes e daquelas" - Cinco aulas de Finanças e Politica Fiscal - Universidade da Bahia - 1959.

No panorama tributário brasileiro nós temos dois tipos de contribuições parafiscais: a dos institutos de previdência a que se refere o artigo 157, item XVI da Constituição Federal e a dos demais órgãos autônomos como Instituto do Pinho, Açúcar 
e do Álcool, Departamento Nacional de Estrada de Rodagem e muitos outros órgãos da administração descentralizada do Estado, criados com base no artigo 30, item III, também da Constituição.

Todos êsses órgãos que arrecadam contribuições parafiscais sáo organismos da administração indireta do Estado que consiste em dotar certos serviços públicos de autoridade orgânica, em face do poder central. O serviço público descentralizado tem perso. nalidade juridica, seu próprio estatuto e seu patrimônio distinto de patrimônio do Estado.

Por quê o Govêrno descentraliza os serviços públicos? Responde-nos o Professor Themistocles Cavalcanti em seu "Tratado de Direito Adninistrativo, volume IV, páginas 27, 2, 28: a) complexidade das funções do Estado; b) multiplicidade dos serviços públicos; e c) necessidade de prover, com maior presteza a realização de certos serviços técnicos, sem os meios e os entraves peculiares ao aparelhamento burocrático".

O ilustre jurista Seabra Fagundes, quando Consultor Gera] da República, em vários pareceres, sintetizou as características dos órgãos da administração indireta ou autárquicos do Estado:

a) criação por ato estatal, importando na outorga de persolidade juridica;

b) desempenho de serviço público, assim considerado por natureza ou por fôrça de lei;

c) execução técnica ou especializada de serviço público;

d) autonomia administrativa ou de direito;

e) autonomia patrimonial que se exprime pela atribuição de recursos financeiros próprios e pela liberdade de aplicação de tais recursos na realização das finalidades do serviço;

f) contrôle estatal, através do qual se tornam efetivos os limites preestabelecidos à autonomia.

A personalidade jurídica das autarquias significa que elas são titulares de direitos subjetivos, pessoas jurídicas de direito público, independentes dêsse ser principal que é Estado, ou melhor
o Executivo.

A criação da autarquia depende de Lei, de acôrdo com o Decreto-lei $n^{\circ} 6 / 016$, de 1943, ao definir essa entidade como:

"serviço público descentralizado, com personalidade de direito público, explicita ou implicitamente reconhecida por Lei".

O Tribunal de Contas ao expedir, em 1957, Instruções sôbre a organização dos processos para julgamento das contas dos administradores das Entidades Autárquicas e das Emprêsas Incorporadas ao Patrimônio Nacional, classificou êsses órgãos da se- 
guinte maneira: a) Entidades Autárquicas de Intervenção Econômica, como o Instituto do Açúcar e do Álcool, Pinho, Mate e Sal; $b$ ) Entidades Autárquicas de Exploração Industrial e de execução de obras públicas como a Comissão de Marinha Mercante, Lóide Brasileiro, Departamento Nacional de Estrada de Rodagem; c) Entidades Autárquicas de Previdência Social, incluindo todos os Institutos de Previdência; d) Entidades de Economia Popular, Crédito e Financiamento como o Banco Nacional do Desenvolvimento Econômico, Crédito Cooperativo; e) Entidades de Ass'stência Social e de Educação Profissional como o S.E.N.A.C, S.E.S.I. e S.E.S.C., embora sejam considerados entidades privadas.

As caracteristicas das contribuições parafiscais são: a) delegação do poder fiscal do Estado a um órgão antônomo; $b$ ) destinação especial dessas receitas aos fins especificos cometidos ao órgão oficial su semi-oficial investido daquela delegação; c) exclusão dessas receitas do orçamento geral.

Há na parafiscalidade, diz o Professor Aliomar Baleeiro", o elemento coativo peculiar a todos os tributos e conseqüentemente o problema consiste na justificação ou explicação de como ela possa afastar os principios jurídicos que, por motivos politicos e históricos, se cristalizaram numa prática secular em tôdas as nações policiadas. Ou, por outras palavras, o importante é investigar-se se há fundamento jurídico para não inclusão das contribuições parafiscais no rol dos impostos e tributos dependentes de autorização orçamentária e de fiscalização pelo Tribunal de Contas, nos países que adotam êsse tipo de contrôle das receitas e despesas públicas".

Desde que a contribuição parafiscal foi criada por lei e a sua cobrança foi delegada a um órgão autônomo com aplicação especifica, a sua cobrança anual independe de autorização orçamentária a que estaria sujeita por fôrça do artigo 141, § 34 da Constituição Federal assim redigido:

“Art. 141, § 34. Nenhum tributo será cobrado em cada exercício sem prévia autorização orçamentária, ressalvada, porém, a tarifa aduaneira e o impôsto por motivo de guerra".

Fugindo à regra da prévia inclusão no orçamento para sua cobrança, as contribuições parafiscais são tributos de natureza especial, pelo menos na estrutura fiscal brasileira, já que em outros paises elas são tributos e, em muitos casos, taxas.

Decorre desta regra constitucional, diz o Professor Aliomar Baleeiro "que uma contribuição parafiscal, no Brasil, há-de ter 
por assento, no fato gerador, uma situação característica de im: pôsto da competência do govêrno que delegou àquela entidade para-estatal, a menos que se revista de caráter de taxa, por corresponder a um benefício prestado, provocado ou pôsto à disposição do contribuinte. $\mathrm{E}$, em ambos os casos, se não existir a autorização orçamentária, há o risco de a cobrança ser repelida pelo contribuinte por meio de recurso ao Poder Judiciário, que tem competência para negar aplicação à lei reputada inconstitucional".

"Todavia, continua o Professor Aliomar Baleeiro, as contribuições exigidas pelos institutos de seguro social estão expressamente previstas na Constituição (art. 157, XVI) em dis posições especificas sôbre a proteção aos trabalhadores, inteira mente à parte das regras de caráter financeiro".

Embora os orçamentos das autarquias não sejam aprovados pelo Parlamento e nem constem do orçamento da Uniáo, estão sujeitos ao contrôle do Tribunal de Contas por fôrça do art. 77
da Constituição Federal.

Aplicando-se o artigo 73 da Constituição que estabelece os principios da unidade e da universalidade do orçamento, a lei ordinária pode estabelecer a obrigatoriedade da inclusão dos orçamentos das autarquias no orçamento federal, já que os seus balan ços econômicos, financeiros e patrimoniais, em virtude do Decreto-lei $n^{\circ} 5.570$, de 1943, devem constar em anexo ao Balanço Geral, publicado pela Contadoria Geral da República.

Copiando o Professor Aliomar Baleeiro, quem melhor es. tudou o problema da parafiscalidade no Brasil, diriamos que "sem dúvida, constitui problema técnico penosíssimo o da inclusão da despesa discriminada, de vários órgãos paraestatais no orçamento da nação. Mas essa dificuldade não é tão insuperável que justifique uma técnica revolucionária, como a parafiscalidade, que rompe com os canônes seculares do direito constitucional e fiscal
acêrca da legitimidade dos impostos e contrôle de sua aplicação".

O ilustre Ministro do Tribunal de Contas do Estado da Guanabara, Dr. José LyRA FILHo tratando do problema da parafiscalidade no Brasil, disse o seguinte: "são incontáveis os malefícios da ruptura causada pela paraflscalidade à unidade e à universalidade do orçamento, bem como ao contrôle dos dinheiros públicos. Não se deve pretender tapar o sol com a peneira, tentando-se ocultar razões políticas a jeito do arbitrio intervencionista do Estado, numa aparência de defesa do bem social e da ordem econômica". Da descentralização funcional do Tribunal de Contas - Revista do Serviço Público - outubro de 1958, pá- 
O Deputado Bilac Pinto, com objetivo de conceituar e caracterizar no direito tributário brasileiro as contribuições parafiscais, apresentou, em 1953, o Projeto de Lei $n^{\circ} 2.760$, que visava:

a) submeter ao contrôle do Tribunal de Contas a aplicação de dinheiro resultante de contribuições parafiscais instituidas por lei federal;

b) definir as contribuições parafiscais;

c) ordenar a intervenção do Govêrno Federal, por intermédio do Ministério da Fazenda, nas instituições que não prestarem contas, ou que as prestarem incorretamcnte, quando houverem recebido contribuições parafiscais;

d) transformar em entidades de direito público tôdas as instituições privadas que se acham no gôzo da percepção de contribuições parafiscais;

e) declarar a responsabilidade pessoal dos dirigentes das entidades reguladas no projeto, quando causarem prejuizos, por dolo, culpa ou violação de lei, regulamento ou normas internas das mesmas.

A proposição considera contribuição parafiscal, qualquer que seja a sua denominação legal, a que reuna as seguintes caracteristicas: a) tenha sido criada ou autorizada por lei federal; b) constitua obrigação de pagamento em dinheiro, sob qualquer forma; c) não figure no orçamento da União; d) seja arrecadacia diretamente pela entidade a que se destine, ou por intermédio de outra entidade de direito privado ou de direito público, ou de autarquia.

Embora o projeto do ilustre Deputado Bilac Pinto não tenha sido aprovado, quase todos os seus objetivos foram atingidos, pois, até mesmo entidades de natureza privadá como o S.E.S.I., S.E.N.A.I., e S.E.S.C. estão obrigadas a prestarem contas ao Tribunal de Contas da União.

No estág;o atual, as contribuições parafiscais continuam à margem das regras de caráter financeiro estabelecidas na Constituição, tornando-se necessário um dispositivo legal que as enquadre no orçamento da União para que elas se revistam das qualidades de um verdadeiro tributo. 